\title{
Experiences of family members of patients with colostomies and expectations about professional intervention
}

\author{
Augusto Ferreira-Umpiérrez ${ }^{1}$ \\ Zoraida Fort-Fort²
}

Objective: the objective was to understand the experience of a group of family members of patients with colostomies, revealing their expectations regarding the intervention of health professionals. Method: qualitative research, with the social phenomenological approach of Alfred Schütz, conducted in Montevideo in 2012; twelve family members of patients with colostomies participated, from an ostomy service of a health institution. Results: the following categories were identified: family ties, trust in the health care team, the nurse as the articulator of the process, the desire to humanize care, and adaptation to new family life. Conclusions: knowing the experience and expectations of the families of colostomy patients was achieved, emphasizing the previous family relationships to build upon them, and the trust in the health team, emphasizing the nurse as articulator of the process. Expectations focused on the desire for humanized care, enhancing adaptation of the nuclear family to the new way of life, restoring and enhancing its strengths, and collaborating in overcoming its weaknesses.

Descriptors: Colostomy; Nursing Care; Life Change Events; Family; Professional-Family Relations.

${ }^{1}$ PhD, Full Profesor, Facultad de Enfermería y Tecnologías de la Salud, Universidad Católica del Uruguay, Montevideo, Uruguay.

${ }^{2}$ PhD, Profesor, Facultad de Enfermería y Tecnologías de la Salud, Universidad Católica del Uruguay, Montevideo, Uruguay.

Corresponding Author:

Augusto Ferreira Umpiérrez

Universidad Católica del Uruguay

Facultad de Enfermería y Tecnologías de la Salud

Av. 8 de Octubre, 2738

CP 11600, Montevideo, Uruguay

E-mail: auferrei@ucu.edu.uy
Copyright (c) 2014 Revista Latino-Americana de Enfermagem This is an Open Access article distributed under the terms of the Creative Commons Attribution Non-Commercial License (CC BY-NC).

This license lets others distribute, remix, tweak, and build upon your work non-commercially, and although their new works must also acknowledge you and be non-commercial, they don't have to license their derivative works on the same terms. 


\section{Introduction}

Colorectal cancer occupies the top position in terms of incidence and mortality, as the third most common cancer in men and second in women throughout the world(1), which signifies a public health problem of particularly complexity. Uruguay does not escape this reality, according to data from the Honorary Committee for the Fight Against Cancer of the country, an organization that integrates the network of Information Systems and Cancer Epidemiology (REDEPICAN), which includes records of Spain and Latin America(2).

This type of cancer, although it is not the only cause, is one of the main reasons for having a colostomy, as one of the interventions indicated to achieve decompression and acceptable evacuation of the affected area, among others. In a health system with epidemiological data as highlighted above, the experience of the people living with a colostomy is a necessary phenomenon to fully understand, to provide the best quality of healthcare. The theory exists with respect to the theme that illuminates the process of care, providing inputs focused on understanding the impact caused by this type of alteration, which is necessary to be understood by the professionals who are part of the healthcare team $^{(3)}$. Some studies emphasize the importance of going beyond the purely biological sphere to move towards a bio-psychosocial approach, where a comprehensive approach, providing support in decision making, becomes relevant to address the care that the user requires ${ }^{(4-5)}$.

In this line, we understand that in order to approach the person with a colostomy, in a comprehensive manner, he must be viewed as a being with others, within a family context to which he belongs and with which he interacts through intersubjective relationships. Family support is fundamental to the acceptance and adaptation to a new way of life(6).

For these reasons, it is necessary that health professionals can understand what it is like to live and to live with an ostomy, in all its multiple dimensions, in a manner that they can think about care that is a response to the needs that are generated, many of which are related to the social and labor environment, sexuality, the fear of rejection ${ }^{(7)}$. It is fundamental to understand the habits, perceptions and attitudes, feelings and emotions demonstrated in the most diverse situations that cross the patients( ${ }^{(8)}$, while understanding those who accompany and sustain them in this life-changing experience $^{(9)}$.
There is evidence of the importance of family involvement in the process in all levels of care, including the home environment ${ }^{(10)}$. Both within the in-hospital care and in the home environment, families are a reference for professionals to enable them to develop their plan of care. Thus, understanding the life of the family members, as relevant actors in the process and emphasized by the patient(11), can generate knowledge that empowers improvements in professional practice and, therefore, achieve better care with benefits to the care recipient, who is supported by the surrounding environment as a biographical place of living and experiences $^{(12)}$. In this vein, health services and professionals must be prepared and organized for this challenge, among other things, because family care is an indespensible support in the process of chronic diseases, positively impacting health systems and public health(13).

Based on the above, this study was guided by the following questions: What is the experience of being a family member of a patient with a colostomy? What are the expectations that the family members have regarding the care from health professionals? How do they visualize family processes in the future? Faced with such questions, and the need to obtain rich and profound information, we chose the qualitative method with a social phenomenological approach, knowing the possibilities of understanding that it offered, as described below.

In this line, the objective of this study was defined as: to know the experience of a group of family members of patients with colostomies, revealing their expectations regarding the intervention of health professionals.

\section{Methods}

This was a qualitative study, based on the premise that the knowledge about the individuals is only possible with a description of the human experience, as it is lived and defined by its actors. We chose the phenomenological method as a theoretical-philosophical reference, in order to understand the reality of everyday life in which the subjects were immersed(14).

The approach chosen was that of the social phenomenology of Alfred Schütz, which offers a systematic method for better understanding the social aspects of human action. This approach provides a pathway that articulates concepts of intersubjectivity, biographical situations, social relationships, expectations and others that can better understand the social world 
of people(15), and in this case, of the patient-family relationships. Understanding of the phenomenon involves an analysis of social behavior in relation to motives and purposes. Schütz distinguished two types of motives in social behavior: those involving action and the purpose, are the "reasons given..." or "reason for..."; and those that assume the scenario of the actors, the environment, the psychic disposition, are the "reasons due to ..." or "reasons because..."(16).

This approach is permeated by concepts that are based on our world that is composed of similarities, with a shared intersubjectivity taking place, where experiences are interpreted reciprocally ${ }^{(16)}$, whereby the reference is optimal for understanding the intersubjective processes that occur in the home environment with the patient. In turn, the attitudes are influenced by the stock of knowledge and the biographical situation of each subject, such that previous lived experiences are stored, determining the relevant elements of the action. These contributions are also significant for understanding the processes of professional - patient - family interaction, contributing to the improvement of professional practice $^{(15)}$

The study was conducted in the city of Montevideo, Uruguay, with twelve participating adult relatives of patients with colostomies, of both sexes, aged 32 to 62 , whose degree of kinship was that of child, spouse, or sibling. Inclusion criteria were: family member over 18 years of age of a patient who was postoperative for three months or more, living with the patient prior to and after surgery, being the family reference for support. Subjects were carefully and intentionally selected from a database known by the researcher, from a stoma service of a health institution in Montevideo, Uruguay. They were selected for their potential to offer profound and detailed information on the subject of interest, given the type of study ${ }^{(17)}$. They were initially contacted by telephone, and then by a visit, to explain the scope of their participation. The data collection was conducted between June and October of 2012, using in-depth interviews of approximately 60 minutes duration. These were established in agreement with the participating subjects and occurred in their home, in a space free of interruptions, ensuring anonymity, privacy and confidentiality of the information provided. The ethical considerations established in Decree No. 379/008 of the country for research involving human subjects were respected, informing participants of the study objectives, scope, and all aspects related to the free and informed consent, which was signed. The study was approved by the Ethics Advisory Committee of the School of Nursing and Health Technologies at the Universidad Católica del Uruguay (Catholic University of Uruguay), with protocol number 005/2012.

Given the type of study, the number of participants was not previously defined, with the collection of data closed when the concerns of the study were answered and the objectives achieved, with responses beginning to become repetitive ${ }^{(18)}$, showing signs of the unveiling of the phenomenon. The interviews were labeled with codes to respect the anonymity of the subjects, identifying them with the letter E (for interview, in the Spanish language), followed by a sequential number from 1 to 12 .

The guiding questions were: What is your experience as a family member of a colostomy patient? What are your expectations regarding the care provided by professionals? How do you see your family from now into the future? These questions were defined in light of the theoretical-philosophical reference chosen, searching for a guide to the unveiling of the phenomenon in question. The interviews were recorded into an electronic device and transcribed accurately, ensuring the integrity of the process.

Data analysis followed the same steps proposed for methods of qualitative, phenomenological data analysis(19) through: careful reading of each interview to grasp the global sense of the lived experience of each subject; clustering of the significant aspects for composing concrete categories; analysis of these categories, seeking the expression of the experience of the family members of colostomy patients; discussion of the results in light of social phenomenology and other references related to the topic. The concrete categories were composed by descriptions that showed the experience of the subjects, naming them to find convergences in light of the reference.

\section{Results}

In the analysis of the interviews, using the phenomenological approach, categories emerged: family ties, trust in the health care team, the nurse as articulator of the process, the desire to humanize care, and, adaptation to the new family life.

Considering the principle concepts of the philosophical reference, it was observed that in each category the "reasons because" (context and personal experiences) and the "reasons for" (projects and expectations) emerged. Excerpts of interviews that led to the categories formed are presented below. 


\section{The family link (reasons because)}

The subjects of the study showed in their discourses the relevance of the prior family ties, from which relationships were built with the patient. Some excerpts of interviews that resulted in this category were:

We always had a very honest, very open relationship, we told each other everything and we had no taboos. That helped a lot, the confidence of knowing that your wife is there for you whatever it is, helps you feel more confident (E2).

It was not easy, not easy, but I'm sure he trusts us. At the beginning it was very hard, this load, sitting down to dinner I would say: but we are old, we did not meet today, it has been twenty years since we are together, you know, the kids they know you as you are (E6).

\section{Confidence in the health team (reasons because)}

This category was comprised of the references given to the health team and the varying levels of trust that was generated in them, with interventions such as:

I was very tranquil because, from the beginning, we saw that the physician and the nurse knew what they were doing. They explained everything, the nurse came twice to our home and gave us confidence, she said that she would accompany us all the way (E4).

It was difficult, not to know anyone and we were alone. He went to the emergency room with horrible pain in his belly and I was separated from him because they had to do things. I felt afraid ... No one explained anything and I was suspicious because they came and went, and they did things and no one explained anything to me (E7).

\section{The nurse as articulator of the process (reasons because)}

The figure of the nurse emerges, in all cases, as the one who articulates, coordinates and conducts the process of support and advice of the care process, as part of the contextual situation of the patient and family. Some excerpts from interviews that emphasized this aspect were:

We were helped so much by the nurse who came, there is one that specializes in this and it's like everything becomes clear. It is relationship that gives you peace. And she talked to both of us, him and me, and clarified the pile of things about which we had doubts. I many times resorted to her to come and mediate because he got so bad when it was soiled (E3).

There were many difficult days. From the first day there was a nurse who was the one who knew the "unnatural anus". She came to our home and explained to us how to use the bathroom, and brought together me, him and my daughter to tell us how provide support (E8).

\section{The desire to humanize care (reasons for)}

Regarding the expectations and projections of the future the desire for humanized care that was maintained arose, among others, in contributions such as the following:

I always had the feeling of the coldness that is in hospitals, where for all that attend you well, there are things that are so cold. What I value and what I would like is that they are more human with us, that is, it is not them, it is that the place is so, so different from one's daily life, no? (E5).

My great expectation is proximity, which occurred in some cases, the young man who assisted us was a luxury, as if he were a family friend, he would come, sit, and explain everything with words like ours (E9).

\section{Adapting to new family life (reasons for)}

The new challenges confronting the family emerged in the following way:

Oh, God, we have so much to do, but what matters is that he is well, operated on, but well and with us ... and as I say, now you have to think ahead, we have to adapt to a couple of things but life goes on (E4).

And you have to get accustomed to it, no? The nurse told us everything would be new, left everything annotated and that is for one study (laughter), you have to get used to wearing rings and those things that are listed here, and I will support you to become more accustomed (E7).

I had so many new things to learn that my desire was to be accompanied, to help me to adapt to new things, which I, now, have to adapt to carrying things when traveling, at the outputs, you have to organize it (E9).

\section{Discussion}

Understanding the life experience of the study subjects, as family members of colostomy patients, allows us to visualize some aspects related to their context and their experiences as a base from which to interact, coexist and contribute to health care, and well as others regarding their expectations and future projections. It has shown the way in which the family experienced the everyday world from the social phenomenological approach(16).

The emerged categories, related to the "reasons because", accounted for the baggage with which the subjects counted, where they constructed their reality beside the patient with a colostomy, showing that family 
members emphasized themes related to family ties, trust in the health team, and the nurse as an articulator of the process.

In relation to family ties we emphasize that they are constructed from what each person brings from his previous experience, taking as its starting point the circumstances of his biographical situation, store of knowledge and previously lived experiences ${ }^{(14,16)}$. People become susceptible, both patients and their relatives, in the absence of prior knowledge of this type of situation, experiencing a lack of adaptation and depression as common findings(20). The family relationships prior to this health experience were fundamental, because from them the subsequent ties were constructed. Evidence exists about the contribution made by prior knowledge of the socio-familiar situation to identify problems, facilitating effective care strategies(21). The health team, and especially those who lead the plan of care of these patients, should have profound knowledge of family issues as its point of special departure, and in each case it is different.

In line with the former, trust in the health team emerged as a highlighted element. The level of confidence that existed was of relevance to the patient and his family. The relationship with the others, permeated by intersubjectivity, denoted a world shared with similars ${ }^{(12)}$, where the professionals play an important role. The foregoing coincides with the contributions of the phenomenology of Schütz, which emphasizes the face-to-face relationship, from the conception that there are always other people who are within our life experience and that collaborate with each person intersubjectively(16). Also, the data were consistent with studies which stressed the challenge of those who shared a space with these patients was to find ways to encourage their participation in social life ${ }^{(4)}$, where the professional emerges as a figure of support for the transition to new experiences, as well as family support $^{(21)}$.

Within the health care team, the nurse emerged as the articulator of the process. The family saw the figure of this professional as the closest, the one that interacted most in relationship to the care and continuous support, coinciding with studies from different $\operatorname{contexts}^{(7,22)}$. People with a colostomy must live the experience of being accepted as a different being, requiring an adjustment of their image and self-concept ${ }^{(5)}$, as well as confronting, along with their family, multiple complications that need to be addressed professionally. In this process, the nurse, through the support relationship, accompanied, educated and supported the family adaptation process, agreeing with authors that emphasized the figure of this professional as advisor, consultant and manager of care in the therapeutic relationship ${ }^{(3,7)}$.

Regarding their expectations, focused from the "reasons for" of the reference, the desire for humanization of the care and adaptation to new family life emerged. Aspects related to the desire for more humane care on the part of the providers of health, both in conventional hospitalization as well as the primary care level, especially emerged in the interviews. Humanizing health care is a challenge facing health systems today. Humanized care, agreeing with the authors, means providing comprehensive care, taking particular account of the human side of the people to whom the care is destined, of their family and their environment ${ }^{(23)}$. From this perspective, it is necessary to generate a space for dialogue with the patient and his family, promoting the expression of feelings and showing respect for his family and personal environment(24).

In this vein, the need for warm, proximal care permeated the interviews conducted in this study. Unveiling of this need before others, that may be of equal or greater concern to the patient, denoted the importance of understanding the phenomenon of study, giving inputs to address the human being in all his dimensions, according to studies highlighting the values and feelings of people $e^{(7,10)}$. It is then a challenge to impregnate the care and professional-patient-family interaction of the human component, rather than focusing on the biological model that transcends, many times, the healthcare institutions.

Finally, the projection that the study subjects made with respect to adaptation to new family life was not minor. In all cases they visualized a shared world, which was confronted by new styles of family life. The desire for a world with others emerged, enveloped by social relationships, in principle in the closest family environment, which was based on the concepts that permeated the philosophical approach(16) of this study. In turn, this led to the importance of adapting to new challenges, in line with studies that highlighted the patient's adaptation to living with an ostomy(25) and the limitations and overcoming of discrimination(6) was highlighted, along with the experiences that took place in the family, in order to learn a new way to live with the fears regarding the possible spread of the cancer that was the motivation for having the colostomy. These needs, with a comprehensive approach to the care of the patients and their families, should be addressed by 
the health team, to plan a process of adaptation and appropriate rehabilitation.

The contributions of this study permitted us to visualize pathways for improvement of professional practice by showing relevant aspects to be taken into account in the plan of care and health care services, by professionals, for such families. However, despite its contributions, this study was limited to a specific field, not offering generalizability due to the method that was used, making it necessary to delve further into the phenomenon studied. The purpose was to develop a profound understanding of the lived experiences, showing one part of the reality, leaving pathways open for further studies on the subject.

\section{Conclusions}

It was possible to know the lived experiences and expectations of the families of patients with colostomies, emphasizing the previous family relationships in order to build upon them, and the trust in the health team, emphasizing the nurse as the articulator of the process. Expectations were centered on the desire for humanized care, enhancing the adaptation of the household to a new way of life, restoring and enhancing their strengths, and helping to overcome their weaknesses.

The findings permitted us to visualize aspects to consider involving health care services and its professionals. It is recommended that health care is addressed taking into account the patient and his family, establishing actions directed toward humanized and holistic care, which is no longer centered in biological reductionism.

\section{References}

1. World Health Organization - International Agency for Research on Cancer. Colorectal Cancer Incidence, Mortality and Prevalence Worldwide. France: Globocan; 2008.

2. Comisión Honoraria de Lucha contra el Cáncer (UR). Informe 2010. Programa de Vigilancia Epidemiológica. Registro Nacionald el Cáncer. Montevideo (Uruguay); 2010.

3. Ferreira A. Proceso de atención al paciente ostomizado: gestión de cuidados integrales. Montevideo: Ed. Psicolibros Waslala; 2011.

4. Kingsley L, Simmons J. Adjustment to colostomy: stoma acceptance, stoma care self-efficacy and interpersonal relationships. J Adv Nurs. 2011; $60(6): 627-35$.
5. Souza PCM, Costa VRM, Maruyama SAT, Costa ALRC, Rodrigues AEC, Navarro. As repercussões de viver com uma colostomia temporária nos corpos: individual, social e político. Rev Eletr Enferm. [Internet]. 2011 [acesso 21 fev 2013]; 13(1):50-9. Disponível em: http://dx.doi. org/10.5216/ree.v13i1.7928.

6. Santana J, Dutra B, Tameirão M, Silva P, Moura I, Campos A. O significado de ser colostomizado e participar de um programa de atendimento ao ostomizado. Cogitare Enferm. 2010;15(4):631-8.

7. Batista MRFF, Rocha FCV, Silva D, Silva F. Autoimagem de clientes com colostomia em relação à bolsa coletora. Rev Bras Enferm. 2011;64(6):1043-7.

8. Maruyama S, Zago M. O processo de adoecer do portador de colostomia por câncer. Rev. Latino-Am. Enfermagem. 2005;13(2):216-22.

9. Bellato R, Maruyama S, Moraes e Silva C, Castro, P. A condição crônica ostomia e as repercussões que traz para a vida da pessoa e sua familia. Ciênc Cuid Saúde. 2007;6(1):40-50.

10. Bachelet V, Collet G, Ribal A. The role of the stoma therapy nurse in the preoperative period. Rev Infirm. 2012;(181):25-6.

11. Silva A, Shimizu H. O significado da mudança no modo de vida da pessoa com estomia intestinal definitiva. Rev. Latino-Am. Enfermagem. 2006;14(4):483-90.

12. Alvarenga $P$, Neide $A$. Perspectiva educativa do cuidado de enfermagem sobre a manutenção da estomia de eliminação. Rev Bras Enferm. 2011;64(2):322-7.

13. Ledón L. Enfermedades crónicas y vida cotidiana. Rev Cubana Salud Pública. 2011;37(4):488-99.

14. Andrade C, Holanda A. Apontamentos sobre pesquisa qualitativa e pesquisa empírico-fenomenológica. Estud Psicol. (Campinas). 2010;27(2):259-68.

15. Camatta M, Nasi C, Schaurich D, Schneider J. Contribuciones de la sociología fenomenológica de Alfred Schütz para las investigaciones en enfermería. Braz J Nurs. 2008;7(2):78-98.

16. Schutz A, Luckmann T. Las estructuras del mundo de la vida. Buenos Aires: Amorrortu; 2009.

17. Martínez-Salgado C. El muestreo en investigación cualitativa: principios básicos y algunas controversias. Ciênc Saúde Coletiva. 2012;17(3):613-9.

18. Noreña A, Alcaraz-Moreno N, Rojas J, Rebolledo D. Aplicabilidad de los criterios de rigor y éticos en la investigación cualitativa. Aquichán-Col. 2012;12 (3):213-27.

19. Merighi MAB, Jesus MCP, Domingos SRF, Oliveira DM, Baptista PCP. Being a nursing teacher, woman and mother: showing the experience in the light of 
social phenomenology. Rev. Latino-Am. Enfermagem. 2011;19(1):164-70.

20. Cotrim H, Pereira G. Impact of colorectal cancer on patient and family: implications for care. Eur J Oncol Nurs. 2008;12(3):217-26.

21. Popek S, Grant M, Gemmill R, Wendel CS, Mohler MJ, Rawl SM, et al. Overcoming challenges: life with an ostomy. Am J Surg. 2010;200(5):640-5.

22. Bachelet $\mathrm{V}$. The training of stomatherapy nurses. Rev Infirm. 2012;(181):29.

23. Borwell B. Rehabilitation and stoma care: addressing the psychological needs. Br J Nurs. 2009; 18(4):S20-2,S24-5.

24. Araújo F de; Ferreira M. Social representations about humanization of care: ethical and moral implications. Rev Bras Enferm. 2011;64(2):287-93.

25. Barnabe N, Dell'Acqua M. Coping strategies of ostomized individuals. Rev. Latino-Am. Enfermagem. 2008; 16(4):712-9. 